\title{
Impact of COVID-19 lockdown on glycemic control in patients with type 1 and type 2 diabetes mellitus: a systematic review
}

\author{
Claudia Eberle* and Stefanie Stichling
}

\begin{abstract}
Background: In 2019, a new virus known as severe acute respiratory syndrome coronavirus type 2 (SARS-CoV-2) has emerged. Coronavirus disease 2019 (COVID-19) was classified as a pandemic in a short period of time. In order to reduce the spread of COVID-19, many countries have imposed a lockdown with movement restrictions, social distancing and home confinement, which has affected routine healthcare activities and everyday life. The aim of this systematic review was to examine the impact of the COVID-19 lockdown on glycemic control in patients with type 1 diabetes (T1D) and type 2 diabetes (T2D).

Methods: We systematically identified studies by searching the databases Cochrane Library, MEDLINE via PubMed, Web of Science Core Collection, EMBASE, and CINAHL until April 2021. We included $n=33$ observational studies of which $n=25$ investigated T1D and $n=8 T 2 D$.

Results: Overall, we analyzed $n=2881$ T1D patients and $n=1823$ T2D patients. Glycemic values in patients with T1D improved significantly during lockdown. Overall, $n=18$ (72\%) T1D studies indicated significant improvements in glycemic outcomes. Meta-analysis revealed a mean difference in $\mathrm{HbA} 1 \mathrm{c}$ of $-0.05 \%(95 \% \mathrm{Cl}-0.31$ to 0.21 ) due to lockdown, and in time in range (TIR) of $+3.75 \%(95 \% \mathrm{Cl} 2.56$ to 4.92). Lockdown determined a short-term worsening in glycemic values in patients with T2D. Overall, $n=4(50 \%)$ publications observed deteriorations in glycemic control. Meta-analysis demonstrated a mean difference in $\mathrm{HbA1c}$ of $+0.14(95 \% \mathrm{Cl}-0.13$ to 0.40$)$ through the lockdown. Moreover, $\mathrm{n}=3$ (75\%) studies reported a not significant deterioration in body weight.

Conclusions: Glycemic values in people with T1D significantly improved during COVID-19 lockdown, which may be associated with positive changes in self-care and digital diabetes management. In contrast, lockdown rather determined a short-term worsening in glycemic parameters in patients with T2D. Further research is required, particularly into the causes and effective T2D management during lockdown.
\end{abstract}

Keywords: COVID-19, Lockdown, Type 1 diabetes, Type 2 diabetes, Glycemic control, Systematic review

\section{Background}

In 2019, a new virus known as severe acute respiratory syndrome coronavirus type 2 (SARS-CoV-2) has emerged in Wuhan, China and was classified as a pandemic and

*Correspondence: claudia.eberle@hs-fulda.de

Medicine With Specialization in Internal Medicine and General Medicine, Hochschule Fulda-University of Applied Sciences, Leipziger Strasse 123, 36037 Fulda, Germany global public health concern in a short period of time [1]. Since then, 142,238,073 coronavirus disease 2019 (COVID-19) cases were confirmed worldwide and 3,032,124 people died (as of April 21, 2021) [1]. One of the most vulnerable people to this virus are those with chronic diseases such as diabetes mellitus [2-4]. Globally, about 463 million adults (20-79 years) are diagnosed with diabetes [5]. Type 1 diabetes mellitus (T1D) accounts for $5-10 \%$ of all diabetes forms and arises mostly in kids and 
young adults [5]. About 1.1 million children and adolescents are diagnosed with T1D worldwide [5]. T1D is a complex disease dependent on immune system beta-cell demolition prompting total insulin lack [6].

However, type 2 diabetes mellitus (T2D) is the most prevalent type of diabetes with ca. 90-95\% [7]. Some risk factors for T2D seem to be rising age, Body Mass Index $(\mathrm{BMI}) \geq 25 \mathrm{~kg} / \mathrm{m}^{2}$, and limited physical activity. T2D arises mainly based on a progressive loss of beta-cell insulin secretion due to insulin resistance [7].

Comorbidities, such as microvascular (eg nephropathy, retinopathy) and macrovascular (eg. cardiovascular disease, stroke, peripheral artery disease) complications are associated with diabetes [6, 8]. Moreover, diabetes leads to a significant increase in COVID-19-related mortality associated with acute respiratory distress syndrome [9].

Optimal glycemic control is important to reduce and prevent diabetic complications and diabetes patients need special care [10]. However, the management of diabetes patients has been changed due to the lockdown imposed to prevent the spread of the pandemic [11]. Governments from different countries have adopted various infection control measures to slow the spread of COVID-19 [11]. Social distancing and quarantine ensure that clinic visits are reduced for fear of infection [12]. Furthermore, the infection control measures might affect physical activity and diet, and there are effects on health care and access to diabetes medication [12]. Due to the contact restrictions and restrictions in the health care area, digital approaches to ensure optimal management of diabetes patients come into focus [12]. Diabetes technology, for example telemedicine, overcomes physical limits and can improve health care access [13].

For example, a study from China found a deterioration in blood glucose control and a high fasting blood glucose during lockdown in T1D patients [14], whereas another study from Spain even found an improvement in glycemic parameters [15]. More and more individual studies from different countries are examining the "lockdown effect" on the management of diabetes patients. In order to generate an overview of the current study situation on this new research topic, we carried out a systematic review. We aimed to investigate the effects of lockdown during the COVID-19 pandemic on glycemic control in patients with type 1 and patients with type 2 diabetes.

\section{Materials and methods} Literature search

Publications were systematically identified by searching the databases Cochrane Library, MEDLINE via PubMed, Web of Science Core Collection, EMBASE, and CINAHL for studies published until April 2021.
Search was conducted using the following keywords: ("diabetes mellitus") AND ("COVID-19" OR "SARSCoV-2") AND ("lockdown" OR "isolation" OR "quarantine" OR "glycemic control"). Medical Subject Headings and Embase Subject Headings terms as well as title/ abstract terms were searched. For example, our search strategy in PubMed was: (("diabetes mellitus") $[\mathrm{MeSH}$ Terms])) AND (("SARS-COV-2"[Title/Abstract]) OR ("COVID-19" [MeSH Terms])) AND ((“lockdown”)[Title/ Abstract])) OR ("isolation")[Title/Abstract] OR ("quarantine")[MeSH Terms] OR ("glycemic control")[Title/ Abstract])).

After searching the five databases, we removed duplicates, screened titles and abstracts for suitability and read the available full texts. In addition, we manually searched reference lists and Google Scholar. Studies were selected by two independent reviewers.

\section{Inclusion and exclusion criteria}

We included peer-reviewed studies published in English and German. We considered observational studies (eg. cohort studies, cross-sectional studies, case-control), retrospective and prospective, that examined the effect of COVID-19-lockdown (infection control measures and their consequences; restrictions, social distancing, quarantine) on glycemic parameters on type 1 and type 2 diabetes patients.

The studies examined a wide variety of outcomes. Glycemic outcomes were heterogeneous. We decided to analyze the most frequently examined outcomes in order to be able to compare the studies as best as possible and to be able to carry out calculations (meta-analysis). Therefore, we analyzed the following most common outcomes: glycated hemoglobin A1c (HbA1c), time in range (TIR) (70-180 $\mathrm{mg} / \mathrm{dl}$ ), and body mass index (BMI)/weight.

In contrast, we have excluded the following aspects: paper which did not specify the type of diabetes, patients with gestational diabetes mellitus and other types of diabetes, duplicates, studies examining other topics and outcomes, the following articles types: poster, abstracts, study protocols, proceeding papers.

\section{Data extraction}

We extracted the following information: year of publication, study region, study design, research objects, patient characteristics, digital care during lockdown, outcomes of interest, key findings (effect of lockdown, statistical information and calculations), study limitations, and hypotheses for underlying reasons regarding the results.

\section{Data synthesis and analysis}

We sorted the publications according to the type of diabetes, outcomes and diabetes technology. The studies 
were classified according to the type of treatment, since technological diabetes management strategies were used here, such as continuous glucose monitoring (CGM) and flash glucose monitoring (FGM), continuous subcutaneous insulin infusion (CSII), hybrid closed loop system (HCL), sensor-augmented pump (SAP), multiple daily injections (MDI) and telemedicine/teleconsulting (not specified).

In addition, we analyzed the impact of lockdown on outcomes compared to the time before lockdown, and performed a meta-analysis on the most common parameters HbA1c and TIR. We took into account all studies that provided complete information on these outcomes. In the calculations, we considered T1D and T2D studies separately. For determining the changes in HbA1c (\%) and TIR (\%), we pooled appropriate studies and calculated the difference in means, with $95 \%$ confidence intervals (CI) before and during/after lockdown. In studies that noted several measurement times during

Table 1 Study characteristics and pooled $\mathrm{HbA1c}$ and TIR values the lockdown, we selected the last measurement time and not the intermediate results.

\section{Results}

\section{Overview characteristics of included studies}

The literature search yielded $n=767$ citations of which $\mathrm{n}=662$ unique citations were screened based on the defined eligibility criteria (see Additional file 1: Fig. S1). After an additive research of reference lists, we identified $n=33$ observational studies of which $n=25$ investigated T1D and $n=8$ T2D. Characteristics of the included publications are provided in Table 1, whereas a detailed description of the studies is exhibited in Additional file 1.

The studies come from the following countries: Italy $(\mathrm{n}=13)$, Spain $(\mathrm{n}=6)$, India $(\mathrm{n}=4)$, Turkey $(\mathrm{n}=2)$, Greece $(n=2)$, China $(n=1)$, Israel $(n=1)$, UK $(n=2)$, Japan $(\mathrm{n}=1)$, and Saudi Arabia $(\mathrm{n}=1)$. In our analysis, we focused on the most common glycemic parameters [HbA1c, TIR (70-180 mg/dl)], and additionally BMI and weight, as these parameters also occurred frequently.

\begin{tabular}{|c|c|c|}
\hline & Type 1 diabetes & Type 2 diabetes \\
\hline Participants (n) & 2881 & 1823 \\
\hline \multicolumn{3}{|l|}{ Diabetes technology during lockdown } \\
\hline CGM (n) & 10 & - \\
\hline FGM (n) & 5 & - \\
\hline $\mathrm{HCL}(n)$ & 2 & - \\
\hline $\operatorname{SAP}(n)$ & 1 & - \\
\hline Different types (n) (CGM, CSII, FGM, insulin pump) & 5 & - \\
\hline Telemedicine $^{a}(n)$ & - & 5 \\
\hline Not described (n) & 2 & 3 \\
\hline \multicolumn{3}{|l|}{ Location } \\
\hline Italy (n) & 11 & 2 \\
\hline Spain (n) & 6 & - \\
\hline Turkey (n) & - & 2 \\
\hline India (n) & 4 & 3 \\
\hline Greece (n) & 1 & 1 \\
\hline China (n) & 1 & - \\
\hline Israel (n) & 1 & - \\
\hline UK (n) & 2 & - \\
\hline Saudi Arabia (n) & 1 & - \\
\hline Japan (n) & 1 & - \\
\hline \multicolumn{3}{|l|}{ Outcomes ${ }^{b}$} \\
\hline $\begin{array}{l}\text { Impact lockdown on HbA1c (\%) } \\
\text { pooled HbA1c levels }\end{array}$ & $\begin{array}{l}\text { Mean difference }-0.05(95 \% \mathrm{Cl}-0.31 \\
\text { to } 0.21) \\
\text { (based on } n=11 \text { studies) }\end{array}$ & $\begin{array}{l}\text { Mean difference }+0.14 \\
\text { ( } 95 \% \mathrm{Cl}-0.13 \text { to } 0.40 \text { ) } \\
\text { (based on } n=8 \text { studies) }\end{array}$ \\
\hline $\begin{array}{l}\text { Impact lockdown on time in range (TIR) (\%), 70-180 mg/dl } \\
\text { pooled TIR values }\end{array}$ & $\begin{array}{l}\text { Mean difference }+3.75 \text { ( } 95 \% \text { Cl } 2.56 \text { to } \\
4.92) \\
\text { (based on } n=18 \text { studies) }\end{array}$ & N/A \\
\hline
\end{tabular}

Italics indicate "pooled" parameters

${ }^{a}$ Telemedical treatment not precisely described

${ }^{b}$ Calculations of the outcomes that have been examined most often 


\section{Type 1 diabetes}

Overall, we analyzed $n=2881$ T1D patients. Of $n=25$ T1D studies, $\mathrm{n}=18$ (72\%) showed clear, significant improvements in glycemic control [14-31], $\mathrm{n}=4(16 \%)$ showed stability (no changes) [32-35] and $n=3(12 \%)$ deteriorations [36-38]. In $n=10$ studies, the patients received CGM treatment, in $n=5$ studies FGM, in $n=2$ studies $\mathrm{HCL}$, in $\mathrm{n}=1$ study SAP, in $\mathrm{n}=5$ studies mixed types of technology such as MDI, CSII, CGM, FGM, insulin pump, and in $n=2$ papers no digital treatments were described. The age groups of the participants were heterogeneous from children to adolescents, young adults to the elderly, and also varied within the studies.

\section{Effect on HbA1c}

For determining the changes in HbA1c (\%) and TIR (\%), we pooled appropriate studies and calculated the difference in means, with 95\% confidence intervals (CI) before and during/after lockdown. Meta-analysis showed that, compared to the time before lockdown, HbA1c values declined with a mean difference of $-0.05 \%$ (95\% CI -0.31 to 0.21 ) based on $\mathrm{n}=11$ eligible studies $[15,21,23$, $25,27,28,30,32,36-38]$. In $n=8$ (73\%) studies in which HbA1c values improved significantly $(\mathrm{P}<0.05)$ due to the "lockdown effect", the improvements ranged between $-0.1 \%$ and $-0.3 \%$.

In total, $\mathrm{n}=2(18 \%)$ studies reported significant $(\mathrm{P}=0.027$ [36] and $\mathrm{P}<0.05$ [38]) deteriorations. Included in the calculations is a study from India [38] that found a large HbA1c deterioration of $+1.2 \%[8.8 \pm 1.3 \%$ vs. $10 \pm 1.5 \%(\mathrm{P}<0.05)]$. According to Verma et al. [38], this is due to the non availability of insulin/glucostrips during lockdown period. If this study is excluded from the calculations, a mean difference of $-0.16 \%$ ( $95 \% \mathrm{CI}-0.25$ to -0.07 ) is obtained (based on $n=10$ studies). Moreover, another study by Hosomi et al. [36] reported HbA1c levels became worse: $+0.12 \%$ in 2020 vs. $-0.09 \% 1$ year ago $(\mathrm{P}=0.027)$.

\section{Effect on time in range (TIR)}

Furthermore, we pooled studies to determine the change in TIR (\%) $(70-180 \mathrm{mg} / \mathrm{dl})$. Based on $\mathrm{n}=18$ eligible studies, the analysis revealed an effect size of mean difference $=+3.75 \%$ (95\% CI 2.56 to 4.92 ) [15-21, 23-27, $29,31-33,35]$. Of these studies, $\mathrm{n}=15(83 \%)$ indicated a significant improvement $(\mathrm{P}<0.05)$ in TIR and $n=3$ (17\%) studies found no significant changes $(\mathrm{P}=0.168$ [32], $\mathrm{P}=0.812$ [33], $\mathrm{P}>0.05$ [35]) due to the COVID-19 lockdown.

\section{Type 2 diabetes}

In general, we analyzed $n=1823$ T2D patients. Of $n=8$ T2D studies, $\mathrm{n}=4(50 \%)$ showed clear deteriorations in glycemic control (HbA1c and mean glucose) [39-42], $\mathrm{n}=2(25 \%)$ showed stability (no changes) [43, 44] and $\mathrm{n}=2(\mathrm{n}=25 \%)[45,46]$ improvements. In $\mathrm{n}=5$ of $\mathrm{n}=8$ T2D studies, the patients received telemedicine care, but telemedicine was not described in detail, and in $n=3$ papers no digital treatments were described.

\section{Effect on HbA1c}

Meta-analysis showed that, compared to the time before COVID-19 lockdown, the lockdown was associated with effect size of mean difference $=+0.14(95 \% \mathrm{CI}-0.13$ to 0.40 ) based on $n=8$ suitable papers.

In total, Rastogi et al. and Psoma et al. reported a significant reduction in $\mathrm{HbA} 1 \mathrm{c}$ values $(6.9 \% \pm 1.3$ vs. $6.7 \% \pm 0.9, \mathrm{P}=0.015[45]$ and $7.8 \%$ (6.9 to 9.4$)$ vs. $7.4 \%$ (6.6 to 8.7), $\mathrm{P}=0.005$ [46]). In contrast, $\mathrm{n}=4$ studies (50\%) observed increased HbA1c values, $\mathrm{n}=2$ of them significant $(\mathrm{P}=0.02[42]$ and $\mathrm{P}=0.002[40])$ and $\mathrm{n}=2$ not significant $(\mathrm{P}=0.253[39]$ and $\mathrm{P}>0.05[41])$.

Moreover, the case-control study by Karatas et al. [40] compared a diabetic $(n=85)$ and a non-diabetic $(n=55)$ group and found that $\mathrm{HbA1c}$ increased significantly in both groups $(+0.71 \% \pm 1.35$ vs. $+0.02 \% \pm 0.19 \%$, $\mathrm{P}=0.002)$.

\section{Effect on BMI and weight}

Overall, $\mathrm{n}=4$ studies reported on BMI or weight. One paper (25\%) [45] reported a significant improvement in BMI (30.6 $\mathrm{kg} / \mathrm{m}^{2} \pm 5.8$ vs. $30.3 \mathrm{~kg} / \mathrm{m}^{2} \pm 5.6, \mathrm{P}=0.01$ ), whereas $\mathrm{n}=3(75 \%)$ studies showed a deterioration in weight (+0.3 kg [44]; +0.54 $\pm 0.95 \mathrm{~kg}[40] ;+0.8 \mathrm{~kg}[39])$, but not significant $(\mathrm{P}>0.05)$.

\section{Discussion}

In general, glycemic parameters in patients with T1D significantly improved during COVID-19 lockdown. Overall, $\mathrm{n}=18$ (72\%) T1D studies indicated clear, significant improvements in glycemic outcomes. Meta-analysis demonstrated a mean difference in HbA1c of $-0.05 \%$ ( $95 \% \mathrm{CI}-0.31$ to 0.21 ) due to "lockdown effect" and in time in range (TIR) of $+3.75 \%$ (95\% CI 2.56 to 4.92 ). In contrast, lockdown determined a short-term worsening in glycemic values in patients with T2D. Overall, $n=4$ $(50 \%)$ publications observed clear deteriorations in glycemic control. Meta-analysis demonstrated a mean difference in $\mathrm{HbA} 1 \mathrm{c}$ of +0.14 (95\% CI -0.13 to 0.40$)$ through the lockdown. Furthermore, $\mathrm{n}=3(75 \%)$ studies reported a (not significant) deterioration in weight between $+0.3 \mathrm{~kg}$ and $+0.95 \mathrm{~kg}$.

COVID-19 lockdown and the associated measures and restrictions led to a change in health care, in people's everyday lives and also had an impact on diabetes management. Our results demonstrate that the effects 
of pandemic lockdown on $\mathrm{T} 1 \mathrm{D}$ and $\mathrm{T} 2 \mathrm{D}$ were very different.

T1D and T2D have a contrasting pathogenesis, which also results in appropriate therapy recommendations with different priorities. Lifestyle changes (eg. diet, exercise) are part of both T1D and T2D management, but the focus of T1D is on insulin therapy [47]. HbA1c could be significantly improved in most studies and this is a promising finding in view of the fact that a good glycemic control reduces the risk of comorbidities and complications as well as progressions of micro- and macrovascular consequences among T1D patients [10]. What is striking about the results is that in almost all cases, T1D patients had digital diabetes management available during the lockdown. Especially digital approaches such as CGM and FGM were often used in T1D therapy.

There are various hypotheses as to why the glycemic values of T1D patients improved as a result of the lockdown. For example, this could be due to more time for self-care and more time to concentrate on T1D management. In the case of children, it may be because the parents who were forced to "stay home" had more time to deal with the disease and family environment may be more attentive in diabetes management [17]. Patients (or their parents) were probably able to balance diet, exercise, and insulin requirements to counteract lockdown consequences such as physical inactivity and the psychosocial impact [15].

Furthermore, the causes can lie in more regular daily lifestyle and a strict daily routine including scheduled meals $[19,21]$. In particular, we noticed that digital treatments for T1D patients (using CGM, FGM, HCL and other methods) probably had a positive impact on glycemic control, which the papers also confirm [21, 26, 27, $35]$. We have also already examined the effect of various digital diabetes therapy approaches on health outcomes of diabetes patients in other papers, and found that these are generally very promising treatments [48, 49]. However, glucose control may be better likely because of better compliance with medications as well as digital solutions and diet during lockdown was observed in type 1 diabetics despite decreased exercise as the former usually is the main determining factor in blood sugar control among type 1 diabetics.

In contrast, two studies [36, 37] that showed worsening glycemic values hypothesized that this could be due to increased stress and decreased physical activity. One study from India [38] leads back the findings to the non availability of insulin/glucostrips during lockdown period.

Our findings for T2D patients obviously differ from those for T1D patients. Here, the analyzed studies tend to show a deterioration in glycemic values and weight/BMI of the patients due to the lockdown period. In general, the pandemic lockdown can have effects on the lifestyle that could affect health and diabetes management, for example changes in the diet (eg. consumption of caloriedense foods), less physical activity, more screen time and weight gain [50]. Observations of lifestyle changes during lockdown in T2D patients of Ghos et al. [51] and RuizRoso et al. [52] showed an increase in vegetable, sugary food and snack consumption. They found an association between levels of foods cravings and snack consumption as well as high percentage of physical inactivity before the COVID-19 lockdown which intensified during the home confinement. Other causes might be insufficient sleep, lack of dietary limitation, increased sitting time, increased socioeconomic difficulties alter healthy nutrition $[40,41]$, the inability to visit hospitals or pharmacies as well as increased anxiety and stress [39]. Besides, there have been other investigations on natural disasters and their effects on diabetes management $[53,54]$. Observations of worsening of glycemic outcomes were made during other stressful situations like earthquakes, hurricane and war.

Furthermore, the measures and restrictions that the governments have issued in the context of the COVID-19 pandemic differ from country to country [11]. Some are more and some are less strict, which might lead to different effects on the health system and peoples lifes. In addition, the individual studies have different investigation periods. Some papers observed the impact of lockdown during lockdown and some after lockdown (compared to pre-pandemic times). However, it must also be considered that, as a reaction to the respective current regional infection process, the lockdowns took place at different periods of time from country to country and also they also differed in number, length and severity. Many of the publications identified come from Italy and Spain. These two European countries had a particularly strict lockdown with severe restrictions for people, e.g. only leaving the apartment for a valid reason (curfew during the day).

Furthermore, it would be interesting and important to investigate pregnant patients with diabetes on this topic, but currently we could only identify one suitable study for this cohort that showed lower diabetes control in patients with gestational diabetes [55].

\section{Limitations}

We only included English and German literature. Furthermore, COVID-19 is a rapidly growing issue. The following must be taken into account when considering our analysis: within the last year, COVID-19-related studies were often published quickly and in a simplified form in order to rapidly generate evidence and derive clinical recommendations, so that formal criteria and 
detailed information (for example on the methodological approach and with regard to the findings) were deferred. The methodology of the studies and the results as well as statistical information have therefore in some cases not been described in detail by the authors.

In addition, we could only identify a few studies with regard to T2D patients. More research is needed here. Overall, the outcomes were partly heterogeneous.

As already mentioned, the local lockdown measures and restrictions are heterogeneous and we could only evaluate the current data situation. Furthermore, the sample sizes were rather small and further investigations on this new topic, in particular on T2D and diabetes in pregnancy, are necessary.

\section{Conclusions}

To our knowledge, this review presents the first overview of the impact of the COVID-19 lockdown on glycemic values of T1D and T2D patients. Glycemic parameters in patients with T1D significantly improved during COVID19 lockdown. In contrast, lockdown determined a shortterm worsening in glycemic values in patients with T2D.

In particular, the causes of the analyzed developments must be further researched. A detailed analysis of factors capable of affecting patients' glycemic values, such as lifestyle changes, is essential. In addition, political preparation for pandemics is important, especially in countries where glycemic parameters have deteriorated due to inadequate health care (e.g. lack of insulin). Further and detailed analyzes of (other) outcomes are necessary. Analyzes are also essential at a later point in time, when more patient data are published and available. Larger studies from different locations are necessary to identify the actual impact of lockdown in people with T1D and T2D on a broader scale.

\begin{abstract}
Abbreviations
BMI: Body mass index; CGM: Continous glucose monitoring; CSII: Continuous subcutaneous insulin infusion; COVID-19: Coronavirus disease 2019; FBG: Fasting blood glucose; FGM: Flash glucose monitoring; HbA1c: Glycated hemoglobin A1c; HCL: Hybrid closed loop system; MDI: Multiple daily injections; SAP: Sensor-augmented pump; SARS-CoV-2: Severe acute respiratory syndrome coronavirus type 2; T1D: Type 1 diabetes; T2D: Type 2 diabetes; TIR: Time in range.
\end{abstract}

\section{Supplementary Information}

The online version contains supplementary material available at https://doi. org/10.1186/s13098-021-00705-9.

Additional file 1: Figure S1. PRISMA flow chart. Table S1. Overview of Type 1 Diabetes studies. Table S2. Overview of Type 2 Diabetes studies.

Acknowledgements

None.

\section{Authors' contributions}

CE designed the systematic review. CE and SS performed the systematic literature search and data extraction of all included studies, and both drafted the first manuscript. CE analyzed, interpreted, and discussed the study results and reviewed the manuscript for intellectual content. C.E. read and approved the final manuscript.

\section{Funding}

Open Access funding enabled and organized by Projekt DEAL.

Availability of data and materials

All data generated and analyzed during are included within the article and its Additional files.

\section{Declarations}

Ethics approval and consent to participate

Not applicable.

\section{Consent for publication}

Not applicable.

\section{Competing interests}

The authors declare that they have no competing interests.

Received: 27 April 2021 Accepted: 10 August 2021

Published online: 07 September 2021

\section{References}

1. World Health Organization. WHO coronavirus (COVID-19) dashboard | WHO coronavirus disease (COVID-19) dashboard. https://covid19.who. int/. Accessed 5 Mar 2021.

2. Verity R, Okell LC, Dorigatti I, Winskill P, Whittaker C, Imai N, et al. Estimates of the severity of coronavirus disease 2019: a model-based analysis. Lancet Infect Dis. 2020;20:669-77. https://doi.org/10.1016/S1473-3099(20) 30243-7.

3. Kleinwechter H, Laubner K. Coronavirus disease 2019 (COVID-19) and pregnancy: overview and report of the first German case with COVID-19 and gestational diabetes. Diabetologe. 2020;16:242-6. https://doi.org/10. 1007/s11428-020-00611-0.

4. Bajgain KT, Badal S, Bajgain BB, Santana MJ. Prevalence of comorbidities among individuals with COVID-19: a rapid review of current literature. Am J Infect Control. 2020. https://doi.org/10.1016/j.ajic.2020.06.213.

5. International Diabetes Federation. IDF diabetes atlas, 9th edition 2019. 2020. https://www.diabetesatlas.org/en/resources/.

6. American Diabetes Association. 2. Classification and diagnosis of diabetes: standards of medical care in diabetes-2020. Diabetes Care. 2020;43:S14-31. https://doi.org/10.2337/dc20-S002.

7. American Diabetes Association. 2. Classification and diagnosis of diabetes: standards of medical care in diabetes-2019. Diabetes Care. 2019;42:S13-28. https://doi.org/10.2337/dc19-S002.

8. Viigimaa M, Sachinidis A, Toumpourleka M, Koutsampasopoulos K, Alliksoo S, Titma T. Macrovascular complications of type 2 diabetes mellitus. Curr Vasc Pharmacol. 2020;18:110-6. https://doi.org/10.2174/1570161117 666190405165151.

9. Gupta R, Ghosh A, Singh AK, Misra A. Clinical considerations for patients with diabetes in times of COVID-19 epidemic. Diabetes Metab Syndr. 2020;14:211-2. https://doi.org/10.1016/j.dsx.2020.03.002.

10. Kleinwechter H. Diabetes and pregnancy —update 2020. Diabetologe. 2020;16:470-7. https://doi.org/10.1007/s11428-020-00629-4.

11. Desvars-Larrive A, Dervic E, Haug N, Niederkrotenthaler T, Chen J, Di Natale A, et al. A structured open dataset of government interventions in response to COVID-19. Sci Data. 2020;7:285. https://doi.org/10.1038/ s41597-020-00609-9.

12. Scott ES, Jenkins AJ, Fulcher GR. Challenges of diabetes management during the COVID-19 pandemic. Med J Aust. 2020;213:56-57.e1. https:// doi.org/10.5694/mja2.50665. 
13. World Health Organization. Telemedicine: opportunities and developments in member states. Report on the Second Global Survey on eHealth 2009. Geneva: World Health Organization; 2010.

14. Tornese G, Ceconi V, Monasta L, Carletti C, Faleschini E, Barbi E. Glycemic control in type 1 diabetes mellitus during COVID-19 quarantine and the role of in-home physical activity. Diabetes Technol Ther. 2020;22:462-7. https://doi.org/10.1089/dia.2020.0169.

15. Pla B, Arranz A, Knott C, Sampedro M, Jiménez S, Hernando I, Marazuela M. Impact of COVID-19 lockdown on glycemic control in adults with type 1 diabetes mellitus. J Endocr Soc. 2020;4:bvaa149. https://doi.org/ 10.1210/jendso/bvaa149.

16. Moreno-Domínguez Ó, González-Pérez de Villar N, Barquiel B, HillmanGadea N, Gaspar-Lafuente R, Arévalo-Gómez M, Herranz L. Factors related to improvement of glycemic control among adults with type 1 diabetes during lockdown due to COVID-19. Diabetes Technol Ther. 2020. https://doi.org/10.1089/dia.2020.0550.

17. Di Dalmazi G, Maltoni G, Bongiorno C, Tucci L, Di Natale V, Moscatiello S, et al. Comparison of the effects of lockdown due to COVID-19 on glucose patterns among children, adolescents, and adults with type 1 diabetes: CGM study. BMJ Open Diabetes Res Care. 2020. https://doi. org/10.1136/bmjdrc-2020-001664.

18. Tinti D, Savastio S, Grosso C, de Donno V, Trada M, Nugnes M, et al. Impact of lockdown during COVID-19 emergency on glucose metrics of children and adolescents with type 1 diabetes in Piediabetesont, Italy. Acta Diabetol. 2021. https://doi.org/10.1007/s00592-021-01702-0.

19. Mesa A, Viñals C, Pueyo I, Roca D, Vidal M, Giménez M, Conget I. The impact of strict COVID-19 lockdown in Spain on glycemic profiles in patients with type 1 diabetes prone to hypoglycemia using standalone continuous glucose monitoring. Diabetes Res Clin Pract. 2020;167: 108354. https://doi.org/10.1016/j.diabres.2020.108354.

20. Predieri B, Leo F, Candia F, Lucaccioni L, Madeo SF, Pugliese M, et al. Glycemic control improvement in Italian children and adolescents with type 1 diabetes followed through telemedicine during lockdown due to the COVID-19 pandemic. Front Endocrinol. 2020;11: 595735. https:// doi.org/10.3389/fendo.2020.595735.

21. Capaldo B, Annuzzi G, Creanza A, Giglio C, de Angelis R, Lupoli R, et al. Blood glucose control during lockdown for COVID-19: CGM metrics in Italian adults with type 1 diabetes. Diabetes Care. 2020;43:e88-9. https://doi.org/10.2337/dc20-1127.

22. Bonora BM, Boscari F, Avogaro A, Bruttomesso D, Fadini GP. Glycaemic control among people with type 1 diabetes during lockdown for the SARS-CoV-2 outbreak in Italy. Diabetes Ther. 2020. https://doi.org/10. 1007/s13300-020-00829-7.

23. Dover AR, Ritchie SA, McKnight JA, Strachan MWJ, Zammitt NN, Wake DJ, et al. Assessment of the effect of the COVID-19 lockdown on glycaemic control in people with type 1 diabetes using flash glucose monitoring. Diabet Med. 2021;38: e14374. https://doi.org/10.1111/ diabetese.14374.

24. Caruso I, Di Molfetta S, Guarini F, Giordano F, Cignarelli A, Natalicchio A, et al. Reduction of hypoglycaemia, lifestyle modifications and psychological distress during lockdown following SARS-CoV-2 outbreak in type 1 diabetes. Diabetes Metab Res Rev. 2020. https://doi.org/10. 1002/diabetesrr.3404.

25. Fernández E, Cortazar A, Bellido V. Impact of COVID-19 lockdown on glycemic control in patients with type 1 diabetes. Diabetes Res Clin Pract. 2020;166: 108348. https://doi.org/10.1016/j.diabres.2020.108348.

26. Longo M, Caruso P, Petrizzo M, Castaldo F, Sarnataro A, Gicchino M, et al. Glycemic control in people with type 1 diabetes using a hybrid closed loop system and followed by telemedicine during the COVID19 pandemic in Italy. Diabetes Res Clin Pract. 2020;169: 108440. https:// doi.org/10.1016/j.diabres.2020.108440.

27. Viñals C, Mesa A, Roca D, Vidal M, Pueyo I, Conget I, Giménez M. Management of glucose profile throughout strict COVID-19 lockdown by patients with type 1 diabetes prone to hypoglycaemia using sensoraugmented pump. Acta Diabetol. 2021;58:383-8. https://doi.org/10. 1007/s00592-020-01625-2.

28. Cognigni M, D’Agostin M, Schiulaz I, Giangreco M, Carletti C, Faleschini E, et al. HbA1c and BMI after lockdown for COVID-19 in children and adolescents with type 1 diabetes mellitus. Acta Paediatr. 2021. https:// doi.org/10.1111/apa.15838.
29. Aragona M, Rodia C, Bertolotto A, Campi F, Coppelli A, Giannarelli R, et al. Type 1 diabetes and COVID-19: the "lockdown effect." Diabetes Res Clin Pract. 2020;170: 108468. https://doi.org/10.1016/j.diabres.2020.108468.

30. Marigliano M, Maffeis C. Glycemic control of children and adolescents with type 1 diabetes improved after COVID-19 lockdown in Italy. Acta Diabetol. 2021. https://doi.org/10.1007/s00592-020-01667-6.

31. Prabhu Navis J, Leelarathna L, Mubita W, Urwin A, Rutter MK, Schofield J, Thabit H. Impact of COVID-19 lockdown on flash and real-time glucose sensor users with type 1 diabetes in England. Acta Diabetol. 2021;58:2317. https://doi.org/10.1007/s00592-020-01614-5.

32. Cotovad-Bellas L, Tejera-Pérez C, Prieto-Tenreiro A, Sánchez-Bao A, Bellido-Guerrero D. The challenge of diabetes home control in COVID-19 times: proof is in the pudding. Diabetes Res Clin Pract. 2020;168: 108379. https://doi.org/10.1016/j.diabres.2020.108379.

33. Christoforidis A, Kavoura E, Nemtsa A, Pappa K, Dimitriadou M. Coronavirus lockdown effect on type 1 diabetes management on children wearing insulin pump equipped with continuous glucose monitoring system. Diabetes Res Clin Pract. 2020;166: 108307. https://doi.org/10.1016/j.diabr es.2020.108307.

34. Wu X, Luo S, Zheng X, Ding Y, Wang S, Ling P, et al. Glycemic control in children and teenagers with type 1 diabetes around lockdown for COVID-19: a continuous glucose monitoring-based observational study. J Diabetes Investig. 2021. https://doi.org/10.1111/jdi.13519.

35. Brener A, Mazor-Aronovitch K, Rachmiel M, Levek N, Barash G, PinhasHamiel $\mathrm{O}$, et al. Lessons learned from the continuous glucose monitoring metrics in pediatric patients with type 1 diabetes under COVID-19 lockdown. Acta Diabetol. 2020;57:1511-7. https://doi.org/10.1007/ s00592-020-01596-4.

36. Hosomi Y, Munekawa C, Hashimoto Y, Okamura T, Takahashi F, Kawano R, et al. Effect of COVID-19 pandemic on the lifestyle and glycemic control in patients with type 1 diabetes: a retrospective cohort study. Diabetol Int. 2020. https://doi.org/10.1007/s13340-021-00507-4.

37. Al Agha AE, Alharbi RS, Almohammadi OA, Yousef SY, Sulimani AE, Alaama RA. Impact of COVID-19 lockdown on glycemic control in children and adolescents. Saudi Med J. 2021;42:44-8. https://doi.org/10.15537/smj. 2021.1.25620.

38. Verma A, Rajput R, Verma S, Balania VKB, Jangra B. Impact of lockdown in COVID 19 on glycemic control in patients with type 1 diabetes mellitus. Diabetes Metab Syndr. 2020;14:1213-6. https://doi.org/10.1016/j.dsx. 2020.07.016.

39. Önmez A, Gamsızkan Z, Özdemir Ş, Kesikbaş E, Gökosmanoğlu F, Torun $\mathrm{S}$, Cinemre H. The effect of COVID-19 lockdown on glycemic control in patients with type 2 diabetes mellitus in Turkey. Diabetes Metab Syndr. 2020;14:1963-6. https://doi.org/10.1016/j.dsx.2020.10.007.

40. Karatas S, Yesim T, Beysel S. Impact of lockdown COVID-19 on metabolic control in type 2 diabetes mellitus and healthy people. Prim Care Diabetes. 2021. https://doi.org/10.1016/j.pcd.2021.01.003.

41. Biancalana E, Parolini F, Mengozzi A, Solini A. Short-term impact of COVID19 lockdown on metabolic control of patients with well-controlled type 2 diabetes: a single-centre observational study. Acta Diabetol. 2020. https://doi.org/10.1007/s00592-020-01637-y.

42. Khare J, Jindal S. Observational study on effect of lock down due to COVID 19 on glycemic control in patients with diabetes: experience from Central India. Diabetes Metab Syndr. 2020;14:1571-4. https://doi.org/10. 1016/j.dsx.2020.08.012.

43. Falcetta P, Aragona M, Ciccarone A, Bertolotto A, Campi F, Coppelli A, et al. Impact of COVID-19 lockdown on glucose control of elderly people with type 2 diabetes in Italy. Diabetes Res Clin Pract. 2021. https://doi.org/10. 1016/j.diabres.2021.108750.

44. Sankar P, Ahmed WN, Mariam Koshy V, Jacob R, Sasidharan S. Effects of COVID-19 lockdown on type 2 diabetes, lifestyle and psychosocial health: a hospital-based cross-sectional survey from South India. Diabetes Metab Syndr. 2020;14:1815-9. https://doi.org/10.1016/j.dsx.2020.09.005.

45. Psoma O, Papachristoforou E, Kountouri A, Balampanis K, Stergiou A, Lambadiari $\mathrm{V}$, et al. Effect of COVID-19-associated lockdown on the metabolic control of patients with type 2 diabetes. J Diabetes Complicat. 2020;34: 107756. https://doi.org/10.1016/j.jdiacomp.2020.107756.

46. Rastogi A, Hiteshi P, Bhansali A. Improved glycemic control amongst people with long-standing diabetes during COVID-19 lockdown: a 
prospective, observational, nested cohort study. Int J Diabetes Dev Ctries. 2020. https://doi.org/10.1007/s13410-020-00880-x.

47. Tan SY, Mei Wong JL, Sim YJ, Wong SS, Mohamed Elhassan SA, Tan SH, et al. Type 1 and 2 diabetes mellitus: a review on current treatment approach and gene therapy as potential intervention. Diabetes Metab Syndr. 2019;13:364-72. https://doi.org/10.1016/j.dsx.2018.10.008.

48. Eberle C, Stichling S, Löhnert M. Diabetology 4.0: scoping review of novel insights and possibilities offered by digitalization. J Med Internet Res. 2020:23(3):e23475.

49. Eberle C, Stichling S. Clinical improvements by telemedicine interventions managing type 1 and type 2 diabetes: systematic meta-review. J Med Internet Res. 2020;23(2):e23244.

50. Lippi G, Henry BM, Bovo C, Sanchis-Gomar F. Health risks and potential remedies during prolonged lockdowns for coronavirus disease 2019 (COVID-19). Diagnosis. 2020;7:85-90. https://doi.org/10.1515/ dx-2020-0041.

51. Ghosh A, Arora B, Gupta R, Anoop S, Misra A. Effects of nationwide lockdown during COVID-19 epidemic on lifestyle and other medical issues of patients with type 2 diabetes in north India. Diabetes Metab Syndr. 2020:14:917-20. https://doi.org/10.1016/j.dsx.2020.05.044.

52. Ruiz-Roso MB, Knott-Torcal C, Matilla-Escalante DC, Garcimartín A, Sampedro-Nuñez MA, Dávalos A, Marazuela M. COVID-19 lockdown and changes of the dietary pattern and physical activity habits in a cohort of patients with type 2 diabetes mellitus. Nutrients. 2020. https://doi.org/10. 3390/nu12082327.

53. Fonseca VA, Smith H, Kuhadiya N, Leger SM, Yau CL, Reynolds K, et al. Impact of a natural disaster on diabetes: exacerbation of disparities and long-term consequences. Diabetes Care. 2009;32:1632-8. https://doi.org/ 10.2337/dc09-0670.

54. Rubinstein A, Koffler M, Villa Y, Graff E. The Gulf War and diabetes mellitus. Diabet Med. 1993;10:774-6. https://doi.org/10.1111/j.1464-5491.1993. tb00163.x.

55. Ghesquière L, Garabedian C, Drumez E, Lemaitre M, Cazaubiel M, Bengler C, Vambergue A. Effects of COVID-19 pandemic lockdown on gestational diabetes mellitus: a retrospective study. Diabetes Metab. 2021;47: 101201. https://doi.org/10.1016/j.diabet.2020.09.008.

\section{Publisher's Note}

Springer Nature remains neutral with regard to jurisdictional claims in published maps and institutional affiliations.
Ready to submit your research? Choose BMC and benefit from:

- fast, convenient online submission

- thorough peer review by experienced researchers in your field

- rapid publication on acceptance

- support for research data, including large and complex data types

- gold Open Access which fosters wider collaboration and increased citations

- maximum visibility for your research: over $100 \mathrm{M}$ website views per year

At BMC, research is always in progress.

Learn more biomedcentral.com/submissions 